\title{
Evidências qualitativas sobre o acompanhamento por doulas no trabalho de parto e no parto
}

\author{
Qualitative evidence of monitoring by doulas \\ during labor and childbirth
}

Raimunda Magalhães da Silva $^{1}$
Nelson Filice de Barros $^{2}$
Herla Maria Furtado Jorge $^{1}$
Laura Pinto Torres de Melo $^{1}$
Antonio Rodrigues Ferreira Junior

Abstract The objective of this study was to conduct a metasynthesis of evidence of the work of doulas assisting women in labor and during childbirth. Articles between 2000 and 2009 were located in the Medline, PubMed, SciELO, and Lilacs databases using the key search words: doulas, gestation, labor, and alternative therapy. Seven articles were selected for the study and four categories were created: the support provided by doulas; the birth mother's experiences; professional relationship: and opinions and experiences of professionals. The doulas offered physical, emotional, spiritual and social support. Experiments showed that the professionals stimulated the mother/child relationship, oriented towards successful breastfeeding, and contributed to the prevention of postpartum depression. Controversy was observed among professionals regarding acceptance of the role of the doula as a member of the obstetrics team. The doula's care was considered innovative, calming, encouraging, and attended all the needs of the pregnant woman. The conclusion is that qualitative studies on the work of doulas are recent, incipient, but revealing as to the important possibility of humanizing labor and childbirth.

Key words Patient companions a.k.a. doulas, Humanized birth, Qualitative research, Labor and childbirth
${ }^{1}$ Programa de a. Av. Washingt Soares 1321, Edson Queiroz. 60811-341
Resumo Objetivou-se elaborar uma metassintese com as evidências sobre o trabalho das doulas no acompanhamento às mulheres em trabalho de parto e de parto. Realizou-se um levantamento nas bases de dados Medline, PubMed, SciELO, Lilacs, usando os descritores doulas, gestação, trabalho de parto, parto e terapia alternativa, no período de 2000 a 2009. Foram selecionados sete artigos e destes emergiram quatro categorias: suporte proporcionado por doulas; experiências das parturientes; relacionamento profissional; e opiniões e experiências dos profissionais. Os principais suportes estavam relacionados aos aspectos físico, emocional, espiritual e social. As experiências evidenciaram que as doulas estimulam a relação mãe e filho, orientam para uma amamentação bem-sucedida e contribuem para prevenir a depressão pós-parto. Observou-se controvérsia entre os profissionais quanto à aceitação deste novo membro na equipe obstétrica, e destacou-se o cuidado como inovador, que acalma, encoraja e supre as necessidades da gestante. Concluiu-se que os estudos qualitativos sobre este tema são recentes, incipientes, mas reveladores de uma importante possibilidade para a humanização do trabalho de parte e parto.

Palavras-chave Acompanhantes de pacientes, Parto humanizado, Pesquisa qualitativa, Trabatho de parto rmsilva@unifor.b

${ }^{2}$ Programa de

Pós-Graduação em Saúde Coletiva, Universidade de Campinas (Unicamp). 


\section{Introdução}

A história do parto passou por uma série de modificações ao longo dos séculos, implicando, entre outras coisas, a substituição do parto do âmbito domiciliar, no qual a parturiente era assistida por parteiras ou por uma mulher de sua confiança, para o hospital, onde fica afastada dos seus componentes familiares e, muitas vezes, sozinha ${ }^{1}$.

Para ancorar a humanização na maternidade, foi sancionada a Lei $n^{\circ} .11 .108$, que preconiza a presença de um acompanhante junto à parturiente durante toda a transição do parto ${ }^{2}$ Com esta regulamentação, observa-se que a atenção obstétrica experimente um período de transição entre o emprego dos aparatos tecnológicos e científicos, que possivelmente beneficiam a assistência de qualidade à mulher, e o reconhecimento de que a assistência à parturiente envolve não só os aspectos físicos, como também o psicológico, o social, o espiritual e o emocional.

O Ministério da Saúde implementa políticas que incentivam o parto natural, a presença do acompanhante, a adaptação ao ambiente hospitalar e a continuidade do cuidado da parturiente no decurso de toda a vivência do parto, com a perspectiva de que variados agentes assegurem o cuidado integral. Com efeito, a mulher poderá escolher um profissional, o companheiro ou um familiar, amiga, parteiras, enfermeiras e, acrescentam-se, as doulas, para lhe dar suporte durante o trabalho de parto e no parto ${ }^{3}$.

A palavra doula tem origem grega e significa "escrava". Naquela cultura, ela assistia a mulher em casa após o parto, auxiliando no cuidado com o bebê e em seus afazeres domésticos. Atualmente, a doula interage com a mulher durante o período perinatal, tanto na gravidez, no parto como durante a amamentação $0^{4}$.

A doula passou a ser reconhecida nos Estados Unidos em 1976, quando Dana Raphael descreveu a experiência de uma mulher que assistiu o trabalho de parto, o parto e a amamentação de outra mulher ${ }^{5}$. De 1980 em diante, as doulas ganharam popularidade, quando mulheres angustiadas com as altas taxas de cesarianas passaram a convidá-las para instruir no seu parto, providenciando suporte no trabalho de parto, apoio nas suas decisões e ajudando-as a evitar procedimentos que as conduzissem a essa cirurgia ${ }^{6}$.

Para a Associação de Doulas da América do Norte (DONA), a doula é considerada uma mulher treinada e experiente em prestar apoio, com capacidade de fornecer contínuo suporte físico, emocional e informativo durante o trabalho de parto e nascimento, mediante o treinamento pela associação DONA, a qual reporta um crescimento exponencial de certificados conferidos, passando de 31, em 1994, para 2.639, em 2009. Além disso, o número de associados passou de 750 para 6.994 no mesmo período, o que demonstra a existência de mercado de trabalho e a valorização do seu papel na assistência à parturiente ${ }^{7}$.

No Brasil, existem cursos para a formação de doulas profissionais ou voluntárias. As entidades "Doulas do Brasil" e a "Associação Nacional de Doulas (ANDO)" são exemplos de locais que fornecem certificados e têm cadastro. Atualmente, existem 201 certificadas pelo curso de formação de "Educadora perinatal", residentes em

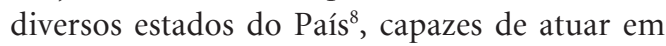
diferentes modalidades, podendo exercer um acompanhamento voluntário no serviço, ou serem contratadas com remuneração por mulheres que desejam receber esse suporte.

Estudos internacionais do tipo metanálise apontaram os benefícios do suporte da doula, demonstrando que as mulheres acompanhadas aumentam duas vezes a chance de ter parto vaginal, comparadas ao grupo que não recebeu este suporte, além de apresentarem melhoria no pósparto, avaliados por meio de características físicas e emocionais9. Outro estudo mencionou que a presença contínua desse gênero feminino reduziu significativamente o uso de analgesia, ocitocina, fórceps e cesariana ${ }^{10}$.

Estudos com abordagem qualitativa sobre doulas e o reconhecimento de seu papel junto às parturientes ainda são incipientes no Brasil e pesquisas desta natureza tornam-se importantes por suprir lacunas de conhecimento e identificar a relevância da sua participação nas equipes obstétricas. Com esse fato questionou-se sobre: quais as pesquisas qualitativas que evidenciam a participação das doulas junto às mulheres em trabalho de parto? Quais as experiências vivenciadas pelas doulas, profissionais e parturientes? Para tanto, realizou-se uma revisão na literatura a fim de identificar estudos qualitativos e constituir uma metassíntese com as evidências sobre o trabalho das doulas no acompanhamento às mulheres em trabalho de parto e no parto.

\section{Metodologia}

Trata-se de uma metassíntese, a qual se originou na Sociologia e que permite utilizar dados de outros estudos qualitativos, referentes a um mesmo assunto ou a temas correlatos ${ }^{11}$, para fazer 
uma leitura crítica e interpretativa dos resultados, com base em rigor metodológico ${ }^{12}$. Assim, esse método leva em conta as similaridades e as diferenças na linguagem, em conceitos, nas imagens e nas ideias em torno da experiência em estudo, para ampliar as possibilidades interpretativas dos resultados e formular narrativas amplas ou teorias gerais ${ }^{13}$.

A elaboração de uma metassíntese consiste: na seleção dos dados com base na sua relevância para responder a uma questão específica; na descrição coerente e integrada de determinados fenômenos ou eventos com característica qualitativa; na integração dos dados; em elaborar uma nova interpretação dos resultados, com inferência derivada dos artigos selecionados para compor o estudo; na análise do pesquisador sobre a interpretação dos dados primários; e constituição de novas interpretações ${ }^{11}$.

Para este artigo, fez-se, nos meses de junho a agosto de 2010, um levantamento de publicações sobre doula nas bases de dados Medline, PubMed, SciELO, Lilacs, nos anos de 2000 a 2009.
Foram buscados os descritores "doulas", "gestação", "trabalho de parto", "parto", "terapia alternativa”, havendo-se identificado 36 publicações com abordagem qualitativa e quantitativa, sendo seis nacionais e 30 internacionais. Destas, após leitura dos resumos, foram pinçados dez publicações que usavam a metodologia qualitativa, os quais compuseram a amostra deste estudo. De posse dos dez resumos, optou-se por critério de inclusão das publicações: ser artigo com abordagem qualitativa publicado em periódico, estar acessível à leitura completa do texto e elucidar a participação da doula. Com este critério, incluíram-se sete publicações e três foram excluídas - uma por se tratar de uma tese e duas por não estarem disponíveis na íntegra para leitura. Os sete artigos (quatro em inglês e três em português) foram organizados em um quadro contendo o nome dos autores, o ano e local da publicação, o objeto de estudo, o núcleo de sentido e os resultados (Quadro 1).

Com o intuito de buscar outros estudos realizou-se um levantamento na base Google acadêmico e encontrou-se sete artigos, uma disser-

Quadro 1. Caracterização dos artigos analisados.

\begin{tabular}{|c|c|c|c|}
\hline $\begin{array}{l}\text { Autor, ano, } \\
\text { local }\end{array}$ & $\begin{array}{l}\text { População estudada e } \\
\text { objeto de estudo }\end{array}$ & Núcleos de Sentido - Temáticas & Resultados \\
\hline $\begin{array}{l}\text { Santos e } \\
\text { Nunes }{ }^{3}, 2009, \\
\text { Bahia }\end{array}$ & $\begin{array}{l}11 \text { Auxiliares/técnicas de } \\
\text { enfermagem } \\
05 \text { Enfermeiras Concepção } \\
\text { dos profissionais sobre a } \\
\text { participação das doulas }\end{array}$ & $\begin{array}{l}\text { Concepção das profissionais de } \\
\text { enfermagem sobre a participação } \\
\text { das doulas na assistência à } \\
\text { mulher no trabalho de parto } \\
\text { - Caracterização do grupo estudado } \\
\text { - Da ideia à realidade da iniciativa } \\
\text { - “doulas na sala de parto": } \\
\text { - Facilidades com a presença das } \\
\text { doulas } \\
\text { - Dificuldades com a presença da } \\
\text { doula }\end{array}$ & $\begin{array}{l}\text { - Muitos enfermeiros estão } \\
\text { despreparados para atuar como } \\
\text { partícipes da implementação da } \\
\text { Política de Atenção a Saúde da Mulher. } \\
\text { - A ideia de implementação das doulas } \\
\text { surgiu da diretoria da maternidade. } \\
\text { - A doula proporcionou conforto } \\
\text { materno, tranquilidade, redução da } \\
\text { ansiedade e mantinham um elo entre } \\
\text { profissionais e pacientes. } \\
\text { - A presença da doula gerou reações } \\
\text { positivas e negativas para os } \\
\text { profissionais. }\end{array}$ \\
\hline $\begin{array}{l}\text { Leão e } \\
\text { Oliveira }^{4}, \\
\text { 2005, São } \\
\text { Paulo }\end{array}$ & $\begin{array}{c}09 \text { Doulas } \\
\text { Perfil das doulas e sua } \\
\text { função }\end{array}$ & $\begin{array}{l}\text { O perfil das doulas e sua função } \\
\text { na assistência a parturiente } \\
\text { - Caracterização do grupo estudado } \\
\text { - Justificativas referidas pelas } \\
\text { doulas para desenvolver sua } \\
\text { atividade } \\
\text { - Atividades que as doulas referiram } \\
\text { desenvolver com as parturientes }\end{array}$ & $\begin{array}{l}\text { - Apresenta a doula como um novo } \\
\text { membro que pode compor a equipe de } \\
\text { saúde na assistência ao parto e } \\
\text { nascimento. } \\
\text { - A maior parte das doulas iniciou o } \\
\text { trabalho por convite de outra doula ou } \\
\text { por vivenciar negativamente a } \\
\text { experiência do seu parto. } \\
\text { - A doula conversava com a parturiente } \\
\text { com o objetivo de acalmar, relaxar, } \\
\text { orientar ou compartilhar experiências e } \\
\text { o acompanhamento ao banho. }\end{array}$ \\
\hline
\end{tabular}


Quadro 1. continuação

\begin{tabular}{|c|c|c|c|}
\hline $\begin{array}{l}\text { Autor, ano, } \\
\text { local }\end{array}$ & $\begin{array}{l}\text { População estudada e } \\
\text { objeto de estudo }\end{array}$ & Núcleos de Sentido - Temáticas & Resultados \\
\hline $\begin{array}{l}\text { Rodrigues e } \\
\text { Siqueira }{ }^{1}, \\
\text { 2008, São } \\
\text { Paulo }\end{array}$ & $\begin{array}{c}20 \text { Parturientes } \\
07 \text { Doulas } \\
\text { Efeitos do acompanhamento } \\
\text { contínuo da doula }\end{array}$ & $\begin{array}{l}\text { Reflexões sobre os possíveis } \\
\text { efeitos benéficos proporcionados } \\
\text { pela presença da doula } \\
\text { - Caracterização do grupo estudado } \\
\text { - Os dizeres sobre si (subjetividade } \\
\text { autorreferida pelas parturientes) } \\
\text { - Os dizeres sobre a presença do } \\
\text { outro (intersubjetividade) }\end{array}$ & $\begin{array}{l}\text { - O acompanhamento da doula propôs } \\
\text { efeitos favoráveis à vivência do ser } \\
\text { materno. } \\
\text { - A dor referida era intensa, } \\
\text { traumática, horrível e inesquecível. } \\
\text { - A doula estabeleceu segurança } \\
\text { confiança, relaxamento e calma. }\end{array}$ \\
\hline $\begin{array}{l}\text { Schroeder e } \\
\text { Bell }^{16}, 2005, \\
\text { Washigton }\end{array}$ & $\begin{array}{c}14 \text { Mulheres encarceradas } \\
\text { Suporte da doula no trabalho } \\
\text { de parto }\end{array}$ & $\begin{array}{l}\text { Suporte da doula no trabalho de } \\
\text { parto de mulheres grávidas } \\
\text { encarceradas } \\
\text { - Caracterização do grupo estudado } \\
\text { - Satisfação com o projeto das } \\
\text { doulas gravidez e nascimento em } \\
\text { custódia } \\
\text { - Separação de bebês: perdas e } \\
\text { luto Planos para a liberdade e } \\
\text { esperanças para o futuro } \\
\text { - Recomendações }\end{array}$ & $\begin{array}{l}\text { - } 14 \text { entrevistadas mostraram satisfeitas } \\
\text { com o suporte da doula. } \\
\text { - As doulas foram essenciais para as } \\
\text { mulheres encarceradas. } \\
\text { - As mulheres vivenciaram a separação } \\
\text { dos filhos com tristeza e ansiedade. } \\
\text { - O suporte da doula ajudou } \\
\text { positivamente no momento do parto } \\
\text { e no cuidado integral a saúde. }\end{array}$ \\
\hline $\begin{array}{l}\text { Papagni e } \\
\text { Bucker }^{15} \\
2006 \\
\text { Alabama }\end{array}$ & $\begin{array}{c}09 \text { Parturientes } \\
\text { Aceitação das doulas por } \\
\text { enfermeiras na concepção de } \\
\text { parturientes }\end{array}$ & $\begin{array}{l}\text { Percepção das parturientes sobre } \\
\text { o nível de aceitação das doulas } \\
\text { pelas enfermeiras } \\
\text { - Caracterização do grupo estudado } \\
\text { - Medidas de suporte } \\
\text { providenciado durante o trabalho } \\
\text { de parto } \\
\text { - Percepções das parturientes sobre } \\
\text { as atitudes das enfermeiras } \\
\text { - Conselho das participantes para } \\
\text { as doulas e enfermeiras } \\
\text { trabalharem juntas }\end{array}$ & $\begin{array}{l}\text { - A doula proporcionou o suporte } \\
\text { físico e emocional. } \\
\text { - As parturientes referiram que o } \\
\text { trabalho da doula ajudou as } \\
\text { enfermeiras a desenvolverem melhor } \\
\text { suas atividades. } \\
\text { - As enfermeiras deveriam se sentir } \\
\text { encorajadas com o suporte das doula. }\end{array}$ \\
\hline $\begin{array}{l}\text { Kayne, } \\
\text { Greulinch e } \\
\text { Albers }^{18} \\
2001, \\
\text { Guatemala, } \\
\text { Estados } \\
\text { Unidos e } \\
\text { Botsuana }\end{array}$ & $\begin{array}{l}\text { Guatemala - } 40 \text { mulheres } \\
\text { Estados Unidos - } 412 \\
\text { mulheres } \\
\text { Botsuana - } 109 \text { Primigestas } \\
\text { Efeitos do suporte da doula } \\
\text { no trabalho de parto }\end{array}$ & $\begin{array}{l}\text { Efeitos positivos do suporte da } \\
\text { doula no parto } \\
\text { - Doulas e suas técnicas de suporte } \\
\text { - Benefícios no pós-parto } \\
\text { - Treinamento e certificação das } \\
\text { doulas }\end{array}$ & $\begin{array}{l}\text { - O suporte contínuo diminuiu o uso } \\
\text { de analgesia, ocitocina e índices de } \\
\text { cesarianas. } \\
\text { - Os hospitais precisam implementar o } \\
\text { programa de doulas ou fazer ajustes } \\
\text { para inserir a doula na sala de parto. } \\
\text { - A presença de um acompanhante } \\
\text { durante o trabalho de parto apresenta } \\
\text { resultados positivos. }\end{array}$ \\
\hline $\begin{array}{l}\text { Ginger }{ }^{17} \text {, } \\
\text { 2005, África e } \\
\text { América }\end{array}$ & $\begin{array}{c}12 \text { Gestantes } \\
12 \text { Recém-mães } \\
\text { Adolescentes } \\
\text { Percepção de adolescentes } \\
\text { grávidas sobre o apoio de } \\
\text { doulas }\end{array}$ & $\begin{array}{l}\text { Percepções de adolescentes } \\
\text { grávidas que receberam o suporte } \\
\text { de doulas comunitárias } \\
\text { - Caracterização do grupo estudado } \\
\text { - Papel social das doulas } \\
\text { - Características do suporte }\end{array}$ & $\begin{array}{l}\text { - As participantes identificaram o } \\
\text { contínuo apoio emocional e físico } \\
\text { durante o trabalho de parto e } \\
\text { nascimento. } \\
\text { - As doulas da comunidade } \\
\text { providenciam cuidados baseados nos } \\
\text { relacionamentos, são modelos } \\
\text { positivos e foram desenvolvem o } \\
\text { suporte primário durante a gravidez, } \\
\text { parto e nascimento. }\end{array}$ \\
\hline
\end{tabular}


tação e dois trabalhos de conclusão de curso. Dos artigos, dois não estavam disponíveis na íntegra e os cinco apresentavam resultados semelhantes aos identificados anteriormente, portanto optamos por considerar aqueles que constavam nas bases de indexação oficiais.

Para proceder à metassíntese, realizaram-se comparações constantes dos dados, análise taxonômica e reciprocidade dos conceitos ${ }^{13}$. Para organizar e analisar os achados empregou-se a análise de conteúdo, usando as fases da pré-análise, exploração do material, tratamento e interpretação dos resultados ${ }^{14}$. Com a convergência dos achados, emergiram quatro categorias de análise: (i) suporte proporcionado pelas doulas ${ }^{1,3,4,15-18}$; (ii) experiências das parturientes que receberam o suporte da doula ${ }^{1,16-18}$; (iii) relacionamento profissional ${ }^{3,4,15,16}$; e, (iv) opiniões e experiências dos profissionais ${ }^{3,4,16}$ (Estas citações referem-se aos sete artigos utilizados no estudo para compor a metassíntese).

\section{Resultados e discussão}

Com a leitura exaustiva do material, elaborou-se uma síntese mostrando a importância da participação das doulas junto às grávidas e parturientes.

Santos e Nunes ${ }^{3}$ entrevistaram 16 profissionais de Enfermagem do Instituto de Perinatologia da Bahia, que haviam tido contato com as doulas, com o objetivo de descrever a ideia da sua participação na assistência à mulher no trabalho de parto. O estudo revelou que muitos enfermeiros estão despreparados para atuar como partícipes na implementação da política preconizada para a atenção à mulher no contexto das maternidades. Este fato evidenciou a necessidade de ações educativas com a equipe de Enfermagem, propiciando discussões que superem os limites de atuação das doulas no cenário pesquisado. As referidas autoras organizaram os dados em quatro categorias: (a) caracterização do grupo estudado - 16 profissionais da saúde do sexo feminino com idade entre 40 e 57 anos com experiência em trabalho de parto; (b) da ideia à realidade da iniciativa "doulas na sala de parto” - a ideia de implantação das doulas na sala de parto surgiu da diretoria do hospital mesmo encontrando dificuldades na equipe multiprofissional desde a inserção à execução do projeto; (c) facilidades com a presença das doulas foi mencionado que elas desempenhavam importante papel, providenciando o conforto materno, tranquilidade, redução da ansiedade e mantinham um elo entre profissionais e pacientes, fazendo com que rompesse o medo e fosse conduzido um parto tranquilo; (d) dificuldades com a presença da doula - para os profissionais, a presença de novos sujeitos na sala de parto resultou em reações positivas e negativas. Não houve interação com a equipe de enfermagem nem com os demais profissionais que atuavam no centro obstétrico. A falta de incentivo financeiro da instituição foi evidenciada por doulas como geradoras de dificuldades, tais como a pouca clareza do seu papel e a diminuição da participação deste membro na equipe, em virtude de que muitas tentavam conseguir um vínculo empregatício na instituição após um período de voluntariado, o que não estava previsto.

Leão e Oliveira ${ }^{4}$ caracterizaram o perfil de nove doulas e sua função. As entrevistas foram conduzidas pela Comissão de Saúde da Mulher do Movimento de Saúde da Zona Leste de um hospital paulista que tinha um grupo de doulas e preconizava o parto natural. Esse estudo apresentou um novo membro que pode compor a equipe de saúde na assistência ao parto e nascimento, podendo desempenhar uma função importante no prénatal e puerpério, e ainda atuar junto à equipe na vigilância dos serviços de saúde. Com os resultados, organizaram três categorias: (a) caracterização do grupo estudado - mulheres, maioria com o ensino fundamental incompleto, com idade entre 26 anos e 71 anos, com experiência com a maternidade e realizando trabalho voluntário; (b) justificativas referidas pelas doulas para desenvolver sua atividade - observou-se que a maioria iniciou esse trabalho por convite de outra doula e por ter vivenciado negativamente o próprio parto. Das nove entrevistadas, sete relataram não ter acompanhado nenhuma parturiente antes de exercer esse papel e que ingressaram no hospital a convite para participar de reuniões, treinamentos e capacitações; (c) atividades que as doulas referiram desenvolver com as parturientes - os achados evidenciaram uma diferença entre o papel da doula no exterior que realiza a assistência junto à equipe, e no Brasil, presta assistência direta com a parturiente. Além disso, foram mencionadas as seguintes atividades: conversar com a parturiente com o objetivo de acalmar, relaxar, orientar ou compartilhar experiências, o acompanhamento ao banho, proporcionar suporte emocional, conforto físico, informações, apoio às decisões e apoio ao parceiro.

Rodrigues e Siqueira ${ }^{1}$ desenvolveram reflexões sobre os possíveis efeitos benéficos de uma escuta responsiva à verbalização da dor, medos e 
seus correlatos na cena do parto. O estudo foi realizado em uma maternidade do Sistema Único de Saúde, na cidade de São Paulo, com 20 parturientes que realizaram partos por via vaginal, e sete doulas. Os autores concluíram que as relações interpessoais no molde do acompanhamento contínuo foram capazes de produzir efeitos favoráveis às vivências do estresse materno, considerando-a como tecnologia apropriada no campo do cuidado. Os resultados respaldaram as seguintes categorias: (a) caracterização do grupo estudado - as participantes possuíam ensino médio incompleto, com faixa etária de 15 a 36 anos e a maioria era de primíparas; (b) os dizeres sobre si (subjetividade autorreferida das parturientes) - perceptíveis em todos os depoimentos, estavam relatos de que a dor era intensa, insuportável, traumática, horrível e inesquecível. Referiram, também, muitas vezes a sensação de exaustão, desfalecimento, de não ter mais forças no momento expulsivo e o medo da morte tanto de si como do filho; (c) os dizeres sobre a presença do outro (intersubjetividade) - ficou atrelado que o acompanhamento por doula foi referido positivamente, possibilitando sensações de segurança, confiança, relaxamento e calma.

Schroeder e Bell ${ }^{16}$ objetivaram implementar e ampliar um programa-piloto com o suporte de doulas no trabalho de parto de grávidas encarceradas em Washington. Os resultados obtidos no estudo constataram que o suporte pode ajudar positivamente no momento do parto e no cuidado integral na saúde, bem como o apoio relacional, pode ser um passo para interromper o ciclo de vícios, negligência, violência, privação econômica e eventual perda das crianças. A parceria do cuidado entre a enfermeira de saúde pública, as doulas e as mulheres pode promover a saúde comunitária e o suporte de serviço, pois elas podem se reunir em prol do benefício da família e da sociedade como um todo. Agruparam os resultados em categorias: (a) caracterização do grupo estudado - entrevistaram 14 mulheres encarceradas e 13 delas relataram questões relativas à pobreza, raça negra, baixo nível de escolaridade, tabagismo, alcoolismo, drogadição e oito não fizeram o pré-natal; (b) satisfação com o projeto das doulas - as 14 entrevistadas se mostraram completamente satisfeitas com o serviço e a indicavam para outras mulheres do mundo; (c) gravidez e nascimento em custódia revelaram as doulas como pessoas de extrema importância na sua experiência do parto; (d) separação de bebês, perdas e luto - as entrevistadas voltaram ao cárcere uma semana após o par- to e nesse momento vivenciaram a separação dos filhos de maneira triste, ansiosa, com sangramento, edemas e extravasamento de leite; (e) planos para a liberdade e esperanças para o futuro - mesmo com depressão e ansiedade, as encarceradas planejavam o futuro, como ter um apartamento, os filhos, terminar o ensino médio, um emprego e também fazer um tratamento adicional, participando de grupo de alcoólicos anônimos; (f) recomendações para mudanças - após a inserção e o reconhecimento do programa, outras ações foram sugeridas tais como: intervir com as grávidas encarceradas e suas crianças; fazer o pré-natal na cadeia; reintegrar a mulher à comunidade; implantar um serviço de saúde mental; criar um programa de tratamento de álcool e drogas; e colocar outras mulheres para ajudar as grávidas enquanto estão encarceradas.

Os autores Papagni e Bucker ${ }^{15}$ desenvolveram um estudo qualitativo para examinar a percepção das parturientes quanto ao nível de aceitação das doulas por enfermeiras. O estudo refletiu sobre as possibilidades de enfermeiras não perceberem que suas atividades podem ser negativas em algumas situações e que o papel da doula é preencher a lacuna na assistência, mediante o suporte emocional que os enfermeiros não oferecem a todas as mulheres. Outra reflexão do artigo sugere que os papéis de cada membro da equipe são diferenciados, podendo trabalhar em conjunto para proporcionar às mulheres um parto seguro e gratificante, de forma que a ação da doula possa aumentar a satisfação da paciente e facilitar o desempenho do enfermeiro. Enviaram 11 questionários e obtiveram retorno de nove e, destes resultados, emergiram as categorias: (a) caracterização do grupo estudado - parturientes brancas, com idade entre 21 e 40 anos, cinco primíparas, quatro multíparas que deram à luz com assistência da doula no hospital norte central de Alabama - Estados Unidos; (b) medidas de suporte providenciado durante o trabalho de parto - vários destes suportes beneficiaram os aspectos físico e psicossocial; (c) percepções das parturientes sobre as atitudes das enfermeiras - a maioria referiu que o trabalho da doula ajudou a desenvolver melhor as obrigações das enfermeiras, mas mostram, também, o ressentimento, a animosidade e a dificuldade de interação das duas categorias; (d) conselho das parturientes para doulas e enfermeiras trabalharem juntas - as enfermeiras deveriam sentir-se encorajadas com a presença da doula e não ameaçadas, pois elas estavam lá para providenciar conforto e suporte para a mãe. 
Kayne et al. ${ }^{18}$ desenvolveram uma metanálise com três estudos realizados na Guatemala, Estados Unidos e Botsuana, com o objetivo de avaliar os efeitos do suporte da doula no trabalho de parto. No estudo realizado na Guatemala participaram 40 mulheres, sendo 20 no grupo casocontrole e 20 no experimental. Nos Estados Unidos, participaram 412 mulheres nulíparas com dilatação de 3 a $4 \mathrm{~cm}$, das quais 212 pertenciam ao grupo ao qual foi prestado o suporte e 200 àquele somente observado. Em Botsuana, participaram 109 primigestas em trabalho de parto não complicado, distribuídas aleatoriamente em um grupo controle e em um experimental. Os resultados apontaram que o suporte no trabalho de parto não é novo e que as mulheres continuam precisando de segurança, aceitação e liberdade. A presença de uma companhia apoiadora durante o trabalho de parto é apresentada como resposta positiva a esta necessidade. Também enfocaram que os hospitais precisam implementar o programa de doulas, ou fazer ajustes, para que esse cuidado seja providenciado durante o trabalho de parto. Os autores organizaram os dados nas temáticas: (a) doulas e suas técnicas de suporte - evidenciou-se o emocional, o conselho e a informação, as medidas de conforto físico, a assistência realizada e o apoio nas decisões; (b) benefícios no pós-parto - percebeu-se melhora nos resultados pós-parto e neonatal, especialmente, na relação mãe e filho, amamentação bem-sucedida e diminuição da incidência de depressão pós-parto; (c) treinamento e certificação das doulas - são convidadas a assistir às aulas de parto e lactação, monitoradas por várias organizações que exploram as experiências individuais e focalizam na provisão de suporte físico e emocional, como também nos princípios básicos da gravidez, infância e pós-parto.

Ginger ${ }^{17}$ descreveu e explorou as percepções de adolescentes grávidas e recém-paridas de baixa renda que receberam apoio de doulas comunitárias, recrutadas e treinadas na comunidade. Estas implementaram modelos integrais de cuidados maternais, incluindo suporte psicossocial apropriado, em especial para aquelas parturientes com as condições sociais pouco adequadas. As percepções foram organizadas da seguinte forma: (a) caracterização do grupo estudado - foram entrevistadas 12 gestantes e 12 recém-mães com idade entre 14 a 18 anos sobre o suporte social da doula; (b) característica do suporte todas as participantes identificaram o suporte da comunidade onde a doula reside, o suporte para as suas necessidades básicas de pré-natal, parto, contínuo apoio emocional e físico durante o trabalho de parto e nascimento; (c) o papel social das doulas - são da mesma etnia das parturientes e vivem dentro da comunidade, providenciam cuidados baseados nos relacionamentos, servem como modelos positivos e foram designadas como participantes de suporte primário durante a gravidez, o parto e o nascimento. Seu suporte foi altamente apreciado e considerado como experiência positiva de vida, que ajudam na provisão de recursos tangíveis e intangíveis.

Fazendo-se uma leitura interpretativa dos resultados encontrados nos sete artigos em estudo, pode-se organizar e agrupar dados que correspondem aos temas a seguir.

Em relação ao suporte proporcionado por doulas, observou-se um conjunto de ações positivas exercidas durante a assistência ao parto. A Figura 1 mostra o diagrama formado por diferentes ações de suporte desenvolvidas por doulas.

Dentre as diversas práticas desenvolvidas por estas mulheres, estavam identificados seis tipos de suporte: I. Físico - inclui técnicas de respiração, posicionamento, caminhada, compressas quentes ou frias e movimentos corporais. II. Social - relaciona o respeito com o familiar e a equipe multiprofissional, favorece ambiente tranquilo, mantém o foco e o interesse na parturiente, demonstra tranquilidade, segurança e carinho. III. Emocional - diminui o medo, a ansiedade, promove encorajamento, contato físico e visual, conversa sincera e transparente, valoriza as atitudes e os comportamentos. IV. De Informação - oferece orientações sobre intervenções obstétricas, posicionamento adequado, esclarece os termos técnicos e tira as dúvidas, fornece informações para familiares e equipe multiprofissional. V. De Apoio às Decisões - enseja espaços para perguntas, respeito às escolhas, às queixas, aos sentimentos, às lamentações e responde com objetividade ${ }^{15,16,18}$. VI. De Práticas Alternativas e Complementares aceita as posições confortáveis escolhidas pela parturiente, realiza massagens de conforto, técnicas de alívio da dor, ensina a movimentar o corpo com aparatos (bola, cavalinho, escada de Ling), promove a benquerença, relaxamento físico e mental, oferece chás de ervas medicinais, homeopatia, musicoterapia, cromoterapia, hidroterapia, meditação, orações e bendição $\mathrm{O}^{1,3,4}$.

No que diz respeito à experiência das parturientes que receberam o suporte da doula, três dos artigos estudados identificaram experiências positivas e significativas quanto à assistência recebida. As parturientes evidenciaram que elas estimulam a relação mãe e filho, orientam para uma 


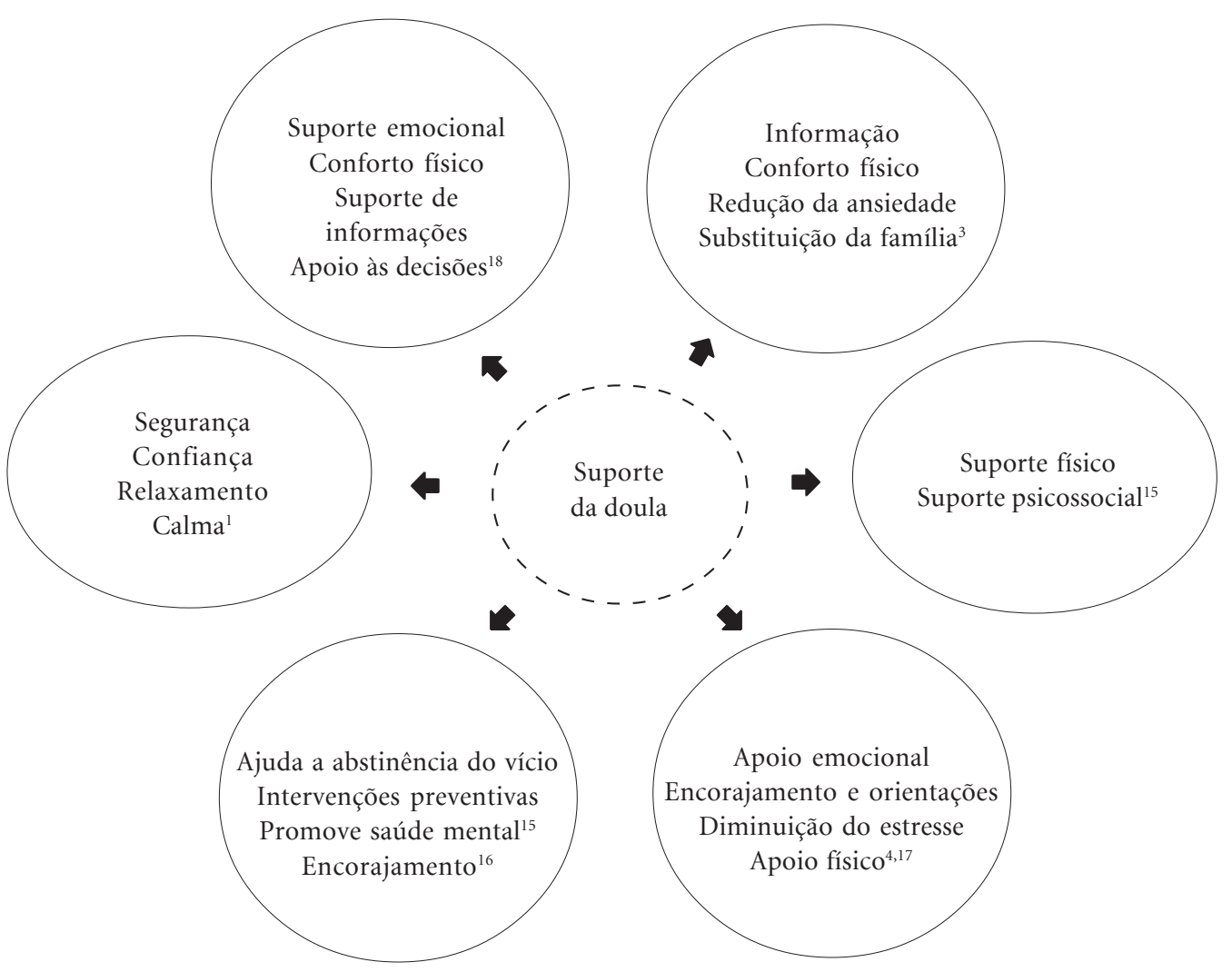

Figura 1. Síntese das categorias sobre o suporte da doula.

Fonte: Artigos selecionados para o estudo.

amamentação bem-sucedida e contribuem para prevenir a depressão pós-parto ${ }^{1,16,17}$.

Em trabalho de Rodrigues e Siqueira ${ }^{1}$, as pacientes relataram com frequência a sensação de muito sofrimento durante o momento expulsivo e que a presença da doula na sala de parto desenvolveu um processo relacional favorável. A comunicação significativa e a presença constante destas fizeram o diferencial no atendimento às parturientes que as compararam com uma "mãe", "anjo" e "fada". A atenção intensiva e a permanência constante significaram uma assistência muito boa e importante naquele momento de "agonia" e "sofrimento".

Schroeder e Bell ${ }^{16}$ descreveram o mecanismo do parto das mulheres encarceradas como sendo uma experiência estressante, insegura, com desconforto, expostas a material tóxico de limpeza, fome constante e sem condições adequadas. A presença da doula ajudou a ter uma expe- riência positiva e todas as parturientes as consideraram como importantes, pois foi a única pessoa que permaneceu junto em todo o processo do nascimento. As mulheres prisioneiras acrescentaram que: Eu teria ficado assustada se estivesse sozinha. Ela me ajudou a ter experiência positiva mesmo eu estando em custódia. A doula me deu contínuo suporte e valorização. Me fez sentir bem de todas as formas. Gostei porque elas ficaram sempre ao meu lado. Ela segurava na minha mão e dizia que estava tudo bem.

Ginger ${ }^{17}$ verificou que o modelo de cuidado baseado na comunidade sugere benefícios adicionais com apoio da doula. As parturientes relataram que esse apoio providencia um suporte fisico e emocional durante a gestação, trabalho de parto e parto, nascimento e amamentação.

Destaca-se no estudo realizado por Rodrigues e Siqueira ${ }^{1}$, em uma maternidade, o fato de que a doula transmitia segurança, confiança, re- 
laxamento e calma à parturiente, o que converge com os resultados encontrados por Schroeder e Bell ${ }^{16}$. Esses autores desenvolveram um programa-piloto, no qual identificaram um excelente suporte, que transmitia calma e encorajamento e supria as necessidades das parturientes. Esses achados indicaram que a atuação desse gênero feminino é relevante e significante para a mulher, antes, durante e após o parto.

Constataram-se divergências do papel da doula no Brasil e no exterior. As práticas realizadas no Brasil correspondem à assistência direta à parturiente, enquanto, no exterior, as doulas são valorizadas e reconhecidas, tanto no suporte oferecido, como na mudança de paradigmas políticos, sociais, éticos e espirituais em relação ao cuidado da mulher que se prepara para o nascimento do filho. Deve-se considerar que a assistência da doula ainda não está presente na Classificação Brasileira de Ocupações $(\mathrm{CBO})^{19}$, denotando dificuldades para a inserção na equipe de saúde das cuidadora das mulheres.

Sumariamente, destaca-se o fato de que a presença de mulheres preparadas e treinadas para esta ação significativa, durante o trabalho de parto e o parto, protege as parturientes de experiências como as relatadas por Moura e Silva ${ }^{20}$, na década de 1980, e Hotimsky e Schraiber ${ }^{21}$, nos anos de 2000:

[...] na fase do parto, entrei em pânico, tomada por sentimento de medo, insegurança e dores que poderiam ter sido aliviadas. Reivindiquei, insistentemente, a presença da minha mãe, que nos corredores externos da maternidade, em companhia do meu marido, escutava meus gritos com pedidos de socorro e de solidariedade. Mas essa atitude tão simples, me fora negada ${ }^{20}$.

São regras do hospital; a lei do acompanhante não vigora; o acompanhante é desnecessário; não é permitida a presença do acompanhante masculino; só pode ficar se for cesárea ${ }^{21}$.

$\mathrm{O}$ relacionamento dos profissionais com as doulas denotou controvérsias quanto à aceitação do seu papel junto à equipe. Santos e Nunes ${ }^{3}$ apontaram que a rejeição dos profissionais da equipe obstétrica pode não estar relacionada com a presença em si, mas à dificuldade em aceitar um novo membro à equipe não havendo nenhuma participação desde a decisão até a inserção das doulas. Os profissionais de Enfermagem, no entanto, reconhecem a importância da presença desta cuidadora na sala de parto, que proporciona suporte emocional permanente, clareza no diálogo, orientações e informações oferecidas: quando a paciente está com aquela dor, elas expli- cam, ajudam a fazer força, ensinam como fazer. Assim, essa contribuição é vista como facilidade para a equipe profissional, de forma que todos os profissionais se beneficiam da ajuda prestada por doulas, desde a realização de procedimentos simples à identificação de necessidades e riscos.

Leão e Oliveira ${ }^{4}$ mencionaram o fato de que as doulas antes de iniciar suas atividades no hospital participavam de reuniões, com o intuito de entrosá-las com os demais profissionais e promover a integração com a equipe assistencial. Essa atitude valoriza o apoio prestado à parturiente $\mathrm{e}$ aos seus componentes familiares. Esses encontros possibilitam esclarecer as funções da doula e da enfermeira, pois a primeira pode conhecer sonhos, medos e desejos da parturiente, enquanto a segunda conhece os procedimentos, as rotinas e os protocolos do hospital; sobretudo, porque a demanda em centros obstétricos é tão intensa que o tempo dedicado pela enfermeira para prover apoio à parturiente não chega a 10\%, demonstrando a necessidade e a importância da assistência contínua oferecida pela doula.

Papagni e Bucker ${ }^{15}$ relataram algumas barreiras dos enfermeiros quanto ao suporte das doulas, especificando pessoal insuficiente, ambiente físico inadequado, atitude negativa em relação à equipe de cuidado e falta de apoio à gestão.

Gilliland ${ }^{6}$ observou, contudo, que, "para doulas e enfermeiros trabalharem juntos como uma equipe, no objetivo de fornecer o melhor possível e cuidar da paciente durante o parto é preciso desenvolver uma relação baseada no respeito mútuo”. A tensão que poderá surgir entre esses profissionais pode ser nociva à saúde emocional e produzir efeitos físicos para a parturiente e o feto, de forma que a doula e a enfermeira precisam aceitar e respeitar o papel de cada profissional de saúde. Os enfermeiros devem reconhecer que a função da doula é importante e poderá aumentar a satisfação da paciente e facilitar o próprio papel, pois as atribuições de cada membro da equipe são diferentes e, se trabalhadas em conjunto, proporcionam às mulheres um parto seguro e gratificante.

As doulas, mesmo sem vínculo institucional, suprem uma lacuna de profissionais nas maternidades e domicílios e beneficiam a mulher grávida, a família e a instituição.

Foi notório nos artigos o fato de que enfermeiros devem ser incentivados a participar de workshops para receber conhecimento sobre o trabalho da doula e desenvolver o relacionamento mútuo, sobretudo, pelo desconhecimento dos princípios da Organização Mundial da Saúde, em 
seu Guia de Assistência ao Parto Normal, para a implementação do trabalho de doulas nas equipes de obstetrícia ${ }^{22}$.

Observou-se que os benefícios do suporte da doula foram mencionados tanto por parturientes quanto por profissionais que vivenciaram o serviço. As gestantes identificaram o fato de que o suporte ajudou na provisão de recursos $^{17}$ e as enfermeiras reconheceram que a presença da doula as libera para realizar suas atividades administrativas com maior aptidão, bem como atender outras pacientes que necessitem de informações no trabalho de parto e no parto, inclusive, sobre o uso de métodos não invasivos e não farmacológicos de alivio da dor ${ }^{7,22}$.

Quanto às opiniões e experiências dos profissionais em relação ao suporte da doula, Schroeder e Bell ${ }^{16}$ identificaram o fato de que elas foram reconhecidas pela equipe obstétrica com distinção pelo excelente suporte garantido às gestantes.

Esta opinião foi ressaltada por Leão e Olivei$\mathrm{ra}^{4}$ como uma atividade inovadora e recente no Brasil, por desempenhar uma função importante na assistência ao pré-natal, puerpério, amamentação e pode atuar junto à equipe na vigilância do serviço de saúde prestado a comunidade.

Para exemplificar a importância desse desempenho, Santos e Nunes ${ }^{3}$ citaram depoimentos de profissionais, reconhecendo que as doulas contribuem com a assistência porque elas estão ali próximas da paciente, elas conseguem até visualizar alguma situação que a gente de repente não está no momento para ver e elas sinalizam. Embora esses autores tenham observado que o trabalho da doula é superimportante alguns profissionais demonstraram dificuldades quanto a sua inserção no cuidado com as mulheres em instituições de saúde e até mesmo a aceitação da presença de acompanhante em maternidade, indo de encontro às recomendações da Política de Humanização no parto ${ }^{23}$ e da Política de Atenção Integral a Saúde da Mulher ${ }^{24}$.

Com o surgimento desse novo suporte na assistência ao parto, configurado nos estudos em análise, indaga-se sobre o porquê das limitações institucionais relativamente à atuação da doula nos espaços que recebem as gestantes no momento singular da vida - o parto e o nascimento. Ante o aceite das parturientes em receber o acompanhamento constante no período do parto, questiona-se sobre as limitações, as fragilidades e as facilidades dos profissionais e dos serviços para aceitar e inserir um novo membro na equipe obstétrica.

\section{Considerações finais}

A metassíntese elaborada com sete pesquisas qualitativas cumpriu o objetivo de produzir evidências sobre a importância, a possibilidade e as vantagens para as parturientes que receberam o suporte das doulas em maternidades ou em outros espaços de assistência à mulher em trabalho de parto e parto. A presença de doulas junto às mulheres é objeto de investigação em diferentes países, contudo os estudos qualitativos sobre o tema são recentes e incipientes.

Constatou-se que a definição de doula é semelhante na literatura, como sendo a mulher que dá suporte físico, emocional, social e espiritual, fornecendo também orientações às parturientes durante o trabalho de parto, parto e pós- parto.

As características satisfatórias do trabalho das doulas foram expressas por parturientes, pelos membros da equipe multiprofissional e pelas próprias doulas. Essa multiplicidade de informações, com considerações positivas conduziu a se reconhecer o suporte da doula à parturiente como favorável e significativo.

Observou-se que muito precisa ser feito para que o papel da doula seja reconhecido e validado em diferentes segmentos da sociedade. No Brasil, a presença de doulas é restrita nas maternidades, mesmo que estas trabalhem de forma voluntária ou contratada pela parturiente. Ainda existe resistência, por parte de alguns profissionais, com a presença de mais uma pessoa para acompanhar, assistir e dar suporte durante o processo de parir.

As mulheres, lentamente, estão assumindo novas formas de atuação e mobilização de recursos formais e informais relativos ao parto, e as instituições raramente identificam esse apelo para abertura de caminhos para outros tipos de trabalho na sociedade. Assim, reafirma-se a necessidade de as instituições de saúde modificarem suas práticas rotineiras, tradicionais, relações de poder e de trabalho, com o objetivo de facilitar e aprimorar o desenvolvimento de ações benéficas e cuidadosas com as pessoas em situação de estresse, de incertezas e com dificuldade de tomar decisões assertivas.

Os estudos de metassíntese representam escassez de publicações nacionais na área de estudo, no que diz respeito às comparações dos achados que visualizem a relação profissional, gestante e doula; estudos que criem possibilidades para formulação de novos pressupostos, paradigmas e políticas públicas no acompanhamen- 
to integral, humanizado e articulado à gestante. Assim, conclui-se que há necessidade de maior incremento nas pesquisas para diversificar as experiências, criar estímulos e motivações para essa função inovadora do suporte prestado pela doula e a recepção dessa prática pelos profissionais no acompanhamento perinatal durante e após o parto.

A presença de um acompanhante, seja membro da família, estranho, amigo, ou mesmo um profissional que acompanhe a mulher no préparto e no parto, diminui significativamente o sofrimento da parturiente, as dores e o uso de procedimentos desnecessários.

As limitações desta pesquisa se inserem no contexto do reduzido número de publicações com abordagem qualitativa sobre doula e na indisponibilidade de outras referências bibliográficas que não constem nos bancos oficiais.

\section{Colaboradores}

RM Silva e NF Barros contribuíram para concepção da ideia, redação e análise crítica do artigo. HMF Jorge, LPT Melo e AR Ferreira Júnior participaram da coleta de dados, organização e análise dos dados.

\section{Agradecimentos}

Agradecemos a CAPES-PROCAD-UNICAMPUNIFOR pelo apoio financeiro e parceria em pesquisa. RM Silva e NF Barros são bolsistas de produtividade em pesquisa do Conselho Nacional de Desenvolvimento Científico e Tecnológico (CNPq). 


\section{Referências}

1. Rodrigues AV, Siqueira AF. Sobre as dores e temores do parto: dimensões de uma escuta. Rev. Bras. Saúde Matern Infantil 2008; 8(2):179-186.

2. Brasil. Lei $\mathrm{n}^{\circ} 11.108$, de 08 de abril de 2005. Altera a Lei n. 8.080, de 19 de setembro de 1990, para garantir às parturientes o direito à presença de acompanhante durante o trabalho de parto, parto e pósparto imediato, no âmbito do Sistema Único de Saúde - SUS. Diário Oficial da República 2005; 8 abr.

3. Santos DS, Nunes IM. Doulas na Assistência ao Parto: Concepção de Profissionais de Enfermagem. Esc Anna Nery Rev Enfermagem 2009; 13(3):582-589.

4. Leão VM, Oliveira SMJV. O Papel da Doula na Assistência a Parturiente. Reme. Rev. Mim. Enferm 2005; 10(1):24-29.

5. Klaus M, Kennel J, Berkowitz G, Klaus P. Maternal assistance and support in labor: father, nurse, midwife, or doula. Clinical Consultations in Obstetrices and Gynecology. 1992; 4(4):211-217.

6. Gilliland AL. Beyond holding hands: the modern role of professional doula. J Obstet Gynecol Neonatal Nurs 2002; 31(6):762-769.

7. Doulas of North America. [site da internet] 2010 [acessado 2010 abr 19]. Disponível em: http://www. dona.org.

8. Doulas no Brasil. [site da internet] 2010 [acessado 2010 abr 18]. Disponível em: http://www.doulas. com.br.

9. Lumley J, Austin MP, Creina M. Intervening to reduce depression after birth: a systematic review of the randomized trials. Int $J$ Technol Assess Health Care 2004; 20(2):128-144.

10. ScottK D, Berkowitz G, Klaus M. A comparison of intermittent and continuous support during labor: a meta-analysis. Am J Obstet Gynecol 1999; 180(5): 1054-1059.

11. Zimmer L. Qualitative meta-synthesis: a question of dialoging with texts. J Adv Nurs 2006; 53(3):311318.

12. Spadacio C, Castellanos MEP, Barros NF, Alegre SM, Tovey P, Broom A. Medicinas Alternativas e Complementares: uma metassíntese. Cad Saude Publica 2010; 26(1):7-13.

13. Sandelowski M, Barroso J. Sandbar Digital Library Project. Qualitative metasummary method. Chapel Hill (USA): University of North Carolina at Chapel Hill School of Nursing. [site na internet] 2004 [acessado 2008 fev 21]. Disponível em: http://sonweb. unc.edu.
14. Bardin L. Análise de Conteúdo. Lisboa: Edições 70; 2008.

15. Papagni K, Bucker E. Doula Support and Attitudes of Intrapartum Nurses: A Qualitative Study From The Patient's Perspective. J Perinat Educ 2006; 15(1): 53-58.

16. Schroeder C, Bell J. Doula Birth Support for Incarcerated Pregnant Women. Public Health Nurs 2005; 22(1):53-58.

17. Ginger B. Perceptions of Social Support from Pregnant and Parenting Teens Using Community-Based Doulas. J Perinat Educ 2005; 14(3):15-22.

18. Kayne MA, Greulinch MB, Albers L. Doulas. An Alternative Yet Complementary Addition to Care During Childbirth. Clin Obstet Gynecol 2001; 44(4): 692-703.

19. Classificação Brasileira de Ocupações. [site na internet] 2011 [acessado 2011 maio 5]. Disponível em: http://www.mtecbo.gov.br/cbosite/pages/home.jsf

20. Moura ERF, Silva RM. Assistência humanizada ao parto a partir de uma história de vida tópica. Acta Paul. Enf 2004; 17(2):141-147.

21. Hotimsky SN, Schraiber LB. Humanização no contexto da formação em obstetrícia. Cien Saude Colet 2005; 10(3):639-649.

22. Organização Mundial da Saúde (OMS). Assistência ao parto normal: um guia prático. Genebra: OMS; 1996.

23. Brasil. Ministério da Saúde (MS). Parto, aborto e puerpério: Assistência Humanizada à Mulher. Brasília: MS; 2001.

24. Brasil. Ministério da Saúde (MS). Política Nacional de Atenção Integral à Saúde da Mulher: princípios e diretrizes. Brasília: MS; 2004.

Artigo apresentado em 20/04/2011

Aprovado em 03/06/2011

Versão final apresentada em 02/07/2011 